\title{
Penggunaan Cetakan Karet dalam Proses Produksi Vulkanisir Ban Alat Berat
}

\author{
Farid Wazdi \\ Jurusan Teknik Mesin, Fakultas Teknik Universitas Pamulang, Tangerang Selatan \\ E-mail: faridwazdi211@gmail.com
}

Masuk:23 Februari 2018 Direvisi :24 April 2018 Disetujui :31 Mei 2018

\begin{abstract}
Abstrak: Bisnis industri vulkanisir ban alat berat mengalami pertumbuhan seiring pertumbuhan binis pertambangan. Seiring dengan pertumbuhan tersebut tuntutan untuk perbaikan di kualitas produk dan harga jual yang kompetitif terus meningkat. Untuk melakukan perbaikan, pengembangan dan inovasi produk, maka penulis melakukan penelitian untuk meneukan metode vulknasir yang mempunyai biaya investasi yang murah dengan kualitas produk yang bagus. Penelitian di fokuskan ke media alat cetak, dimana saat ini yang sudah ada hanyalah media metal atau besi dimana biaya investasinya ini sangat tinggi. Penelitian dilakukan dengan pengamatan ke media cetak yang digunakan produk-produk berbahan dasar karet lainnya. Selain itu informasi-informasi lainnya terus dikumpulkan baik dari pameran industri karet, internet dan komunikasi dengan praktisipraktisi yang telah lama dan kaya pengalaman diindustri vulkanisir ban alat berat.

Dari hasil pengamatan maka media yang akan didalami dalam penelitian ini adalah cetakan berbahan dasar karet. Penelitian bahan dasar cetakan dan pengembangan mesin untuk menunjang penerapan pemakaian cetakan karet untuk proses produksi vulkanisir ban alat berat.

Hasil percobaan dalam proses produksi dan pemantauan kualitas cetakan dan produk vulkanisir yang dihasilkan menunjukan hasil yang bagus dengan biaya produksi dan investasi yang rendah. Kualitas produk menggunakan cetakan karet ini menunjukan performan yang bagus baik di opersional maupun dari segi umur pemakaian dimana kualitas ban vulkanisisr metode cetakan karet ini diatas $60 \%$ umur baru, bahkan mendekati umur ban baru. Investasi dari penggunakan cetakan ini juga jauh lebih efisien disbanding penggunaan cetakan dari logam. Keuntungan lainnya adalah cetakan ini mudah dibuat dan untuk penyediaan atau produksinya cepat, hanya 1 x24 jam sudah bisa digunakan
\end{abstract}

Kata kunci: Vulkanisir, cetakan, karet, umur pemakaian, biaya investasi

\begin{abstract}
The heavy duty tire retreading industry business has growing along with the growth of the mining business. Along with these growth demands for improvements in product quality and competitive selling prices continue to increase. To make improvements, development and product innovation, the authors conducted a study to determine the vulknasir method which has a low investment cost with good product quality. The research focused on the media of printing equipment, where currently there are only metal or iron media where the investment costs are very high. The research was conducted by observing the print media used by other rubber-based products. In addition, other information continues to be collected both from the rubber industry, internet and communication exhibitions with long-standing practitioners who are rich in experience in the tire tire retreading industry.

Results of the observation, the media that will be explored in this research are molds made from rubber. Research on basic materials for molds and machine development to support the application of rubber molds to the production process of vulcanizing tire machines.

The experimental results in the production process and monitoring the quality of the mold and the vulcanized products produced show good results with low production and investment costs. The quality of products using rubber molds shows good performance both in operational and in terms of service life where the vulcanized tire quality of the rubber molding method is above $60 \%$ new age, even nearing the age of new tires. The investment from using these prints is also far more efficient than the use of metal molds. Another advantage is that this mold is easy to make and for the supply or production is fast, only $1 x$ 24 hours it can be used.
\end{abstract}

Keywords: Retread, mould, rubber, life performance, cost 


\section{PENDAHULUAN}

Persaingan dunia usaha saat ini makin ketat. Faktor harga, kualitas produk dan pelayanan selalu menjadi tuntutan pelanggan untuk memilih membeli suatu produk. Pengembangan kualitas produk yang disertai dengan efisiensi biaya menjadi salah satu prioritas semua perusahaan dalam mempertahankan dan mengembangkan bisnisnya. Semua perusahaan berusaha menekan biaya operasional, termasuk perusahaan yang bergerak pada industri tambang. Biaya penyediaan ban untuk kendaraan alat berat termasuk dalam tiga besar komponen biaya terbesar dalam operasional perusahaan tambang pada umumnya setelah bahan bakar minyak (solar) dan investasi alat berat.

Pengembangan untuk memperpanjang umur pemakaian ban terusa dilakukan, diantaranya adalah dengan retreading atau Vulkanisir. Vukanisir merupakan proses pada ban bekas pakai dimana kondisi tapan ban (tread) yang sudah tipis di berikan lapisan karet baru pada bagian tapak ban (tread) tersebut, sehingga ban tersebut bisa dipergunakan kembali untuk operasional kendaraan. Vulkanisir menjadi alternatif untuk menurunkan biaya operasional perusahaan tambang. Ban-ban yang masih memiliki kondisi casing (kontruksi ban) bagus akan divulkanisir dari pada harus membeli ban baru. Biaya vulkanisir sekitar $30 \%-40 \%$ dari biaya pembelian ban baru, dengan umur pemakaian rata-rata diatas $70 \%$ umur pemakaian ban baru. Efisiensi biaya dengan penggunaan proses vulkanisir telah menjadi pilihan penghematan biaya bagi perusahaan di industri pertambangan. Saat ini di Indonesia sudah ada sekitar 10 perusahaan yang bergerak pada industri vulkanisir untuk alat berat.

Dalam bisnis vulkanisir mengenal beberapa metode dalam proses produksinya. Metode press moulding (menggunakan cetakan metal), proses precure tread dan metode cap \& groove sudah berkembang. Setiap sistem mempunyai kelebihan dan kekurangannya masing-masing.

Metode press moulding adalah metode vulkanisir dimana proses curing (pemasakan) dan kompon baru dilakukan pada sebuah media cetakan yang terbuat dari metal. Pola tapak ban yang dihasilkan berasal dari cetakan metal tersebut. Kelebihan metode ini adalah umur cetakan yang tahan lama dan hasil produk yang presisi. Tetapi metode ini membutuhkan biaya investasi yang mahal. Cetakan metal untuk ban ukuran besar berharga ratusan juta rupiah dan butuh waktu pembuatan yang lama (sekitar 6 bulan).

Metode precure tread adalah metode vulkanisir yang menggunakan lapisan tread yang sudah tercetak pola tapaknya. Pada proses vulkanisirnya lapisan tapak ban yang sudah memiliki pola tersebut direkatkan dengan ban menggunakan bahan perekat. Metode ini cepat dalam dalam waktu proses produksinya tetapi memilki kelemahan dalam segi kualitas umur pemakaian. Telapak yang direkatkan pada ban bekas sering lepas dalam pemakaian di kendaraan alat berat. Berat kendaraan dan medan operasional tambang sangat tidak cocok terhadap metode ini. Metode ini banyak dilakukan pada ban kendaraan kecil seperti mobil penumpang dan truk.

Proses Cap \& Groove adalah proses vulkanisir dimana kompon diproses pemasakan tanpa menggunakan cetakan. Pola tapak ban diproses secara manual atau dengan mesin setelah proses pemasakan selesai. Kualitas umur pemakaian produk dengan metode ini rata-rata sama dengan metode press moulding, tapi secara penampilan dan operasional produk metode ini masih kurang, karena sebagian besar proses pembuatan pola tapak ban dilakukan manual. Mesin pembuat pola tapak atau grooving mesin untuk vulkanisir ban alat berat biaya investasinya sangat mahal.

PT. X adalah perusahaan distributor ban baru alat berat (Off the Road) dari suatu merk terkenal. Saat ini dengan banyaknya produk ban baru dari Cina dan India dengan harga yang ditawarkan jauh lebih murah mengakibatkan kompetisi yang ketat pada penjualan ban baru. Pelanggan banyak yang memilih menggunakan ban dengan harga murah sambil mencoba kualitas dari produk tersebut. Kondisi ini membuat angka penjualan ban baru pada PT. X mengalami penurunan. Dengan kondsi ini PT. X melihat suatu potensi bisnis dengan mendirikan pabrik vulkanisir ban alat. berat.

Dalam tahap awal bisnis vulkanisirnya. PT. X menggunakan teknologi precure tread dan cap \& groove dalam proses produksi vulkanisirnya. Setelah berjalan beberapa tahunternyata perkembangan bisnis vulkanisir dengan menggunakan kedua metode tersebut berkembang lambat. Karena produk yang dihasilkkan tidak mempunyai nilai lebih dari segi harga maupun kualitas dibandingkan produk kompetitor. Bardasrkan hal inilah maka dilakukan penelitian untuk mendapatkan metode vulkanisir yang mampu memberikan nilai lebih dibandngkan produk kompetitor.

Berdasarkan kelebihan dan kekurangan masing-masing teknologi serta dengan mempertimbangkan kemampuan keuangan perusahaan maka dicari alternatif teknologi yang bisa memenuhi kebutuhan dari perusahaan yaitu kualitas produk yang tinggi disertai biaya investasi yang rendah. Dengan mempelajari teknologi yang digunakan pada produk karet lainnya, maka dilakukanlah analisa dan percobaan terknologi tersebut ke dalam proses vulkanisir ban alat berat dengan melakukan modifikasi yang dibutuhkan. Teknologi tersebut adalah dengan menggunakan cetakan dari bahan dasar karet untuk proses vulkanisir ban alat berat. 
40 | Farid Wazdi, Penggunaan Cetakan Karet dalam Proses Produksi....,

\section{METODOLOGI}

\section{Sistematika Penelitian}

Peneliatian ini dilakukan sesuai dengan diagram alir sebagai berikut

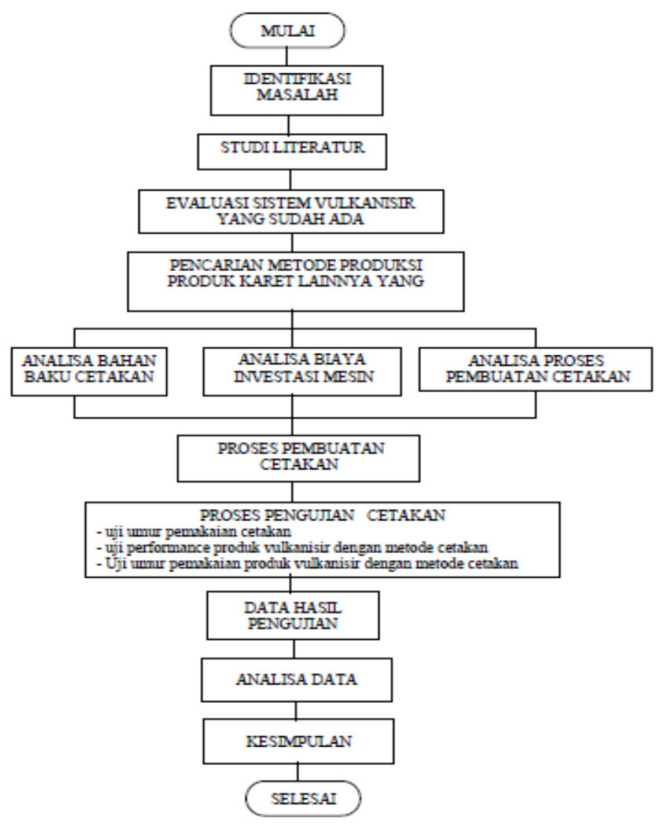

Gambar 1. Diagram Alir Penelitian

\section{Analisa Proses}

Proses retreading seperti yang diulas pada ban sebelumnya, merupakan flow umum yang digunakan oleh vulkanisir ban alat berat. Perbedaan yang terjadi pada umumnya terletak pada proses Buffing, building dan Curing. Perbedaanya bisa dilihat pada table berikut;

Tabel 1. Proses dan perlengkapan sistem vulkanisir

\begin{tabular}{|l|l|l|l|}
\hline \multicolumn{1}{|c|}{ Proses } & $\begin{array}{l}\text { Precure } \\
\text { Tread }\end{array}$ & \multicolumn{1}{|c|}{$\begin{array}{c}\text { Cap \& } \\
\text { Groove }\end{array}$} & Press Mould \\
\hline $\begin{array}{l}\text { Bagian yg di } \\
\text { buffing }\end{array}$ & $\begin{array}{l}\text { Bagian } \\
\text { crown }\end{array}$ & $\begin{array}{l}\text { Hingga area } \\
\text { shoulder }\end{array}$ & $\begin{array}{l}\text { Hingga area } \\
\text { bead }\end{array}$ \\
\hline $\begin{array}{l}\text { Bentuk } \\
\text { (contour) } \\
\text { hasil buffing }\end{array}$ & $\begin{array}{l}\text { Flat } \\
\text { (rata) }\end{array}$ & $\begin{array}{l}\text { Membulat } \\
\text { (curve) }\end{array}$ & $\begin{array}{l}\text { Membulat } \\
\text { (curve) }\end{array}$ \\
\hline $\begin{array}{l}\text { Material di } \\
\text { building }\end{array}$ & $\begin{array}{l}\text { precure } \\
\text { tread }\end{array}$ & $\begin{array}{l}\text { rubber strip } \\
\text { compound }\end{array}$ & $\begin{array}{l}\text { rubber strip } \\
\text { compound }\end{array}$ \\
\hline $\begin{array}{l}\text { Perlengkapan } \\
\text { curing }\end{array}$ & envelope & envelope & $\begin{array}{l}\text { tanpa } \\
\text { envelope }\end{array}$ \\
\hline
\end{tabular}

\section{Analisa Mesin \& Investasi.}

Saat produksi pertama kali, PT X menggunakan metode Precure Tread dan Cap \& Groove, dengan alasan investasi mesin lebih kecil dibandingkan press mould/remould. Kualitas yang dihasilkan lebih bagus karena menggunakan sistem dingin. Karena alasan di atas maka inovasi produk yang akan dilakukan diupayakan bisa menggunakan mesin yang sudah ada dan tidak ada investasi untuk pembelian equipment dan mesin khusus. Mesin yang sudah ada dan bisa digunakan; 


\section{Mesin OTR Buffing}

Berfungsi untuk membuang sisa karet pada ban yang akan divulkanisir dan membuat kasar pada permukaannya.

\section{Tire Stand.}

Sebagai gantungan ban pada saat proses preparation sebelum proses building

2. Rubber strip OTR Building mesin.

Mesin untuk proses pemberian karet tread baru pada ban yang di vulkanisir.

3. Envelope spreader.

Mesin pembuka envelope (karet pembungkus ban) untuk loading / unloading ban ke envelope.

\section{Autoclave.}

Mesin untuk proses vulkanisasi.

\section{Analisa Produk Hasil Cetakan Karet}

Sifat karet yang fleksibel dan mempunyai bermacam variasi karakter dan sifat tergantung jenisnya membuat karet banyak digunakan sebagai bahan dasar berbagai produk termasuk sebagai media pembuat produk tersebut. Media tersebut diantaranya adalah cetakan berbahan dasar karet. Produk tersebut antara lain ;

1. Benda seni (ukiran, patung, dll).

2. Mainan anak-anak.

3. Suku cadang kendaraan.

4. Dan lain sebagainya.

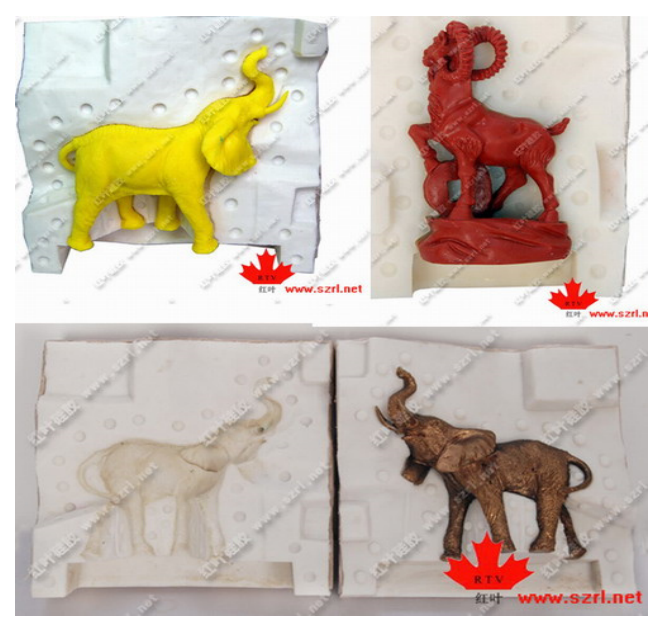

Gambar 2. Cetakan karet produk mainan anak

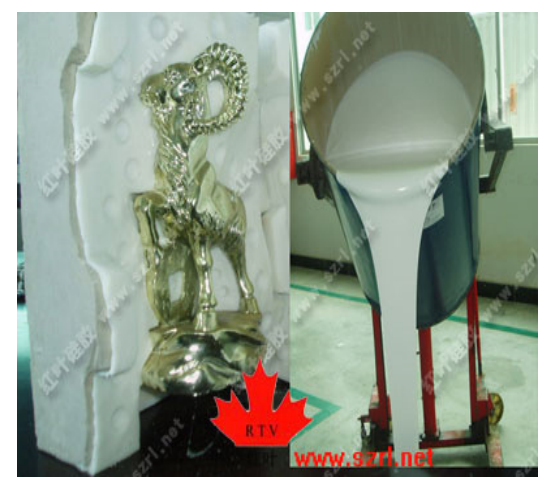

Gambar 3. Catakan karet produk patung

Banyaknya produk yang menggunakan cetakan karet ini karena melihat keunggulan yang dimiliki bila menggunakannya. Keunggulan cetakan berbahan dasar karet ini adalah 
1. Kemudahan dalam proses pembuatan cetakan.

2. Biaya mould jauh lebih rendah dari cetakan yang terbuat dari logam.

3. Hasil produk yang dihasilkan sangat menyerupai bentuk produk aslinya.

\section{HASIL DAN DISKUSI}

Berdasarkan analisa mengenai sifat karet dan adanya produk lain yang menggunakan cetakan yang berbahan dasar karet walaupun produk yang dihasilkan sangat berbeda dari segi ukuran. Kelebihan dari mould berbahan dasar karet adalah kemudahan dalam proses pembuatan cetakan itu sendiri. Bahan karet yang melewati proses curing akan lebur dan masuk ke semua celah produk yg akan ditiru sehingga hasil proses menggunakan cetakan tersebut akan menyerupai aslinya.

\section{Penentuan Bentuk Cetakan}

Penentuan disini bukannlah pada bentuk pola tapak yang akan dibuat tapi apakah cetakan yang akan dibuat terdiri dari berapa bagian atau belahan. Selan itu perlu ditentukan hingga bagian mana pada ban yang akan dicetak oleh cetakan.

\section{Jumlah Bagian atau Belahan pada Cetakan}

Pada produk lain seperti yang dibahas pada Bab 3, cetakan umumnya dibuat minimal dua bagian. Hal ini bertujuan untuk kemudahan pada proses loading / unloading. Salah satu unsur terpenting pada proses vulkanisasi adalah tekanan diterima produk harus merata disemua bagian. Tidak meratanya tekanan akan menimbulkan proses vulkanisasi tidak sempurna dan bentuk produk yang dihasilkan tidak seperti yang diharapkan.

Proses vulkanisasi pada produk lain yang menggunakan cetakan dari karet adalah menggunakan mesin curing press, dimana cetakan berbahan dasar karet diberi casing dari logam yang akan diberi tekanan. Tekanan hidrolik tidak langsung pada cetakan karet tapi menekan metal yang berfungsi sebagai casing cetakan karet.

Proses press moulding yang terjadi pada pada produk lain tersebut tidak bisa diaplikasikan pada sistem moulding yang akan di buat ini karena PT. X tidak mempunyai mesin vulkanisasi dengan sistem press moulding. PT. X hanya mempunyai autoclave (chamber) untuk proses vulkanisasinya.

Tabel 2. Perbedaan proses kerja Curing Mould Press dengan Autoclave

\begin{tabular}{ccc}
\hline $\begin{array}{c}\text { Proses } \\
\text { Kerja }\end{array}$ & $\begin{array}{c}\text { Curing Mould } \\
\text { Press }\end{array}$ & Autoclave \\
\hline $\begin{array}{c}\text { Sumber } \\
\text { Panas }\end{array}$ & $\begin{array}{c}\text { Electric / Steam } \\
\text { Hydrolic }\end{array}$ & Electric / Steam \\
Tekanan & $\begin{array}{c}\text { Pressure } \\
\text { Kecepatan }\end{array}$ & Air Pressure \\
$\begin{array}{c}\text { Rambat } \\
\text { Panas }\end{array}$ & $\begin{array}{c}\text { Directional / } \\
\text { langsung }\end{array}$ & $\begin{array}{c}\text { Tidak langsung / } \\
\text { media udara }\end{array}$ \\
\hline
\end{tabular}

Dengan kondisi mesin ada tersebut maka akan lebih baik kualitasnya bila mould yang dibuat tidak berupa potongan tapi satu kesatuan utuh. Problem yang akan dihadapi dengan membuat mould hanya terdiri satu bagian utuh adalah saat memasukan dan mengeluarkan (loading/unloading) produk dari dan ke mould tersebut. Problem tersebut harus dicari jalan keluarnya dengan melakukan analisa jenis karet yang dipilih dan hingga bagian mana pada ban mould tersebut akan dibuat.

\section{Penentuan Bagian Pada Ban yg Dibuat Mould}

Seperti yang sudah dibahas pada bab sebelumnya bahwa proses retreading adalah proses pemberian karet tread ban pada ban dengan kondisi tread sudah tipis. Dengan melihat tersebut berarti area yg wajib dibuat cetakan adalah area crown /tapak ban. Pada sistem remould, area yang cetak hingga area bead, tapi hal tersebut tidak mungkin dibuat bila cetakan hanya terdiri dari satu bagian utuh. Bagian yang mungkin dibuat dengan cetakan karet ini adalah hingga bagian shoulder.

Alasan lain agar cetakan dibuat hingga area shoulder adalah sebagai berikut :

1. Penampilan tread pattern pada produk akan terlihat menarik dan bagus .

2. Posisi ban saat dimasukan dalam mould akan tepat (center) posisinya, karena ban yang akan diproses akan dijepit dan kemungkinan cetakan bergeser sangat kecil. 
3. Karet tread baru akan mendapat tekanan yang merata dan membantu meningkatkan kualitas produk pada saat proses vulkanisasi.

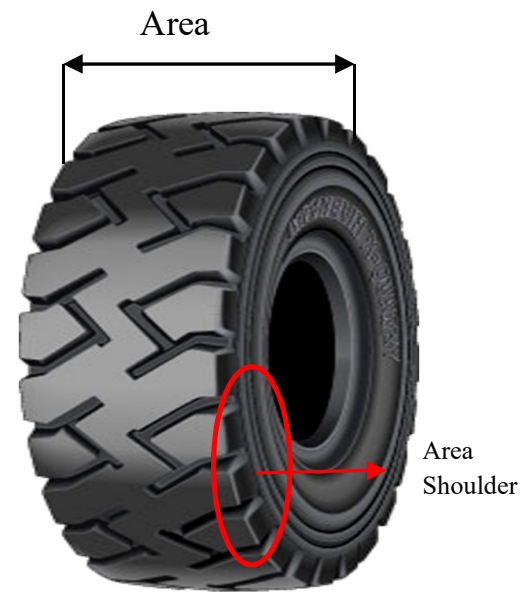

Gambar 4. Area crown dan shoulder

Kesulitan yang akan dihadapi dengan cetakan hingga bagian shoulder adalah pada saat proses loading/unloading produk di mesin envelope spreader, karena cetakan harus ditarik / dibuka agar ban bisa masuk. Sifat tahan sobek \& elastisitas cetakan sangat penting dalam proses ini karena jika tidak mould akan sobek saat di tarik.

\section{Penentuan Jenis Karet Bahan Cetakan}

Cetakan yang akan dibuat untuk digunakan dalam proses vulkanisisr harus mempunyai sifat-sifat sebagai berikut ;

1. Mempunyai sifat elastistas tinggi. Sifat ini diperlukan pada saat proses loading / unloading ban yang diproses ke dalam cetakan tersebut.

2. Kekuatan sobek. Sifat ini diperlukan agar tidak mudah sobek saat di envelope spreader untuk proses loading / unloading ban.

Sebenarnya untuk jenis karet yang mempunyai sifat elastisitas dan kekuatan sobek adalah NR (Natural Rubber), tapi karena NR mempunyai beberapa kelemahan dalam proses produksi maka dipilihlah IR (Isopropene Rubber). Sifat yang dimiliki oleh Isopropene Rubber sebagai berikut ;

Tabel 3. Sifat Isopropene Rubber (IR)

\begin{tabular}{ll}
\hline \multicolumn{1}{c}{ Kelebihan } & \multicolumn{1}{c}{ Kekurangan } \\
\hline Tensile strength & $\begin{array}{l}\text { Ketahanan terhadap } \\
\text { ozon, sinar matahari }\end{array}$ \\
Kepegasan (resilience & \\
Ketahanan sobek) & \\
Fleksibilitas & $\begin{array}{l}\text { Ketahanan terhadap } \\
\text { minyak }\end{array}$ \\
$\begin{array}{l}\text { Tidak berbau } \\
\text { Lebih mudah diproses } \\
\text { dibandingkan NR }\end{array}$ & \\
\hline
\end{tabular}

Setelah jenis karet sebagai bahan dasar kompon mould, maka material pendukung pembuatan kompon cetakan seperti filler, anti oksidan dan sebagainya dikonsultasikan ke Compounder (ahli pembuat kompon). Compounder meramu Iso Propenen Rubber dengan material lainnya untuk disesuaikan dengan sifat fisik yang diiinginkan dan menyesuaikan kondisi dan proses produksi terutama proses curing di autoclave (curing temperature dan curing time) dan mesin extruder yang digunakan diproses. 


\section{Metode Pembuatan Cetakan}

Sesuai dengan referensi dari proses pembuatan cetakan karet di produk lain dan keistimewaan sifat karet maka cetakan karet ini akan dibuat dengan cara menempelkan kompon ke ban baru. Kompon yang sudah terpasang di ban baru akan diberi tekanan dan diproses vulkanisasi bersama dengan ban baru tersebut. Dengan cara tersebut diharapkan tread pattern akan tercetak sempurna pada cetakan.

Sebagai mana dibahas sebelumnya bahwa pembuatan cetakan karet ini bertujuan untuk mencari invosi produk tanpa banyak berinvestasi, maka dari itu semua proses harus menggunakan mesin yang sudah ada. Proses pemberian kompon ke ban yg sedang di vulkanisir menggunakan mesin rubber strip OTR building, dimana mesin yang pula digunakan untuk pemberian kompon tapak ban ke ban yang sedang diproses.

Pada pembuatan cetakan akan ditempel langsung pada ban baru, maka harus diperhatikan bahwa setelah proses curing selesai, cetakan yang dibuat harus bisa dibuka dan dipisahkan dan ban baru tersebut. Kerusakan pada ban baru harus dihindarkan karena harga ban baru yang sangat mahal. Agar tidak terjadi lengket antara ban baru dengan karet cetakan pada proses curing, ban baru diberi cairan silikon dengan cara di seluruh permukaan yang akan bersentuhan dengan karet. Silikon akan memberi lapisan yang diantara ban dan karet baru sehingga diharapkan ban baru tidak akan rusak karena lengketnya karet setelah proses curing.

Resiko terjadinya trap air (udara terjebak) saat proses vulkanisasi bisa dicegah dengan pemberian benang katun pada ban baru di area bagian dalam. Benang katun ini terhubung hingga ke area yang tertempel kompon cetakan. Saat proses curing, karet lumer dan karena ada tekanan udara maka karet akan masuk mengisi kesemua bagian. Kondisi seperti ini memungkinkan adanya udara terjebak yang akan menyebabkan pattern yang terbentuk pada mould tidak sempuna. Bentuk cacat yang mungkin timbul adalah lubang baik berupa cekungan maupun berupa pori-pori yang besar di permukaan cetakan nantinya.

Karena telah diberi silikon maka karet yang akan ditempel saat proses building akan mengalami kesulitan. Untuk menghindari hal ini maka permukaan ban diberi cairan lem. Setelah proses curing selesai lem akan menempel pada permukaan cetakan dan hal itu tidak mempengaruhi kualitas.

Bila semua proses awal sudah selesai maka proses building bisa dimulai. Di proses ini lembaran kompon dimasukan ke mesin extruder. Kompon menjadi lunak karena di dalam extruder terdapat screw yang berputar sehingga timbul gesekan antar kompon dengan screw dan rumah screw. Kompon lunak tersebut di berikan dinginkan saat melewati cooling drum. Selanjutnya kompon ditempel ke ban setelah melewati conveyor. Kompon yang ditempel di ban langsung di tekan dengan roll sticher agar lebih rekat sekaligus membuang udara yang terperangkap.

\section{Metoda Curing}

Sesuai dengan pembahasan sebelumnya bahwa proses curing dengan menggunakan autoclave menggunakan envelope. Setelah produk masuk ke dalam cetakan maka udara dalam cetakan akan disedot menggunakan vacuum pump. Dalam kondisi vacuum, kompon mendapat tekanan ke dalam dan ini bertujuan untuk melekatkan kompoun ke ban yang akan bentuk patternnya. Fungsi envelope disini hanya sebagai ruang udara yang akan divacuum. Envelope diberi seal dan dipastikan tidak ada kebocoran.

\section{Metoda Finishing}

Setelah sekitar 22 jam proses curing selesai dan produk bisa dikeluarkan dari autoclave. Produk harus didinginkan sekitar 24 jam, tujuannya agar saat di spreader envelope dan cetakan tidak robek. Karet yang sedang hangat atau panas akan lebih lunak dan mudah untuk robek.

\section{Uji Coba Kualitas}

Kualitas sistem vulkanisir menggunakan cetakan dari karet ini akan diukur dari kualitas cetakan itu sendiri dan kualtas produk vulkanisir yang dihasilkan.

\section{Kualitas Cetakan}

Dalam percobaan yang pertama kali terjadi kegagalan proses karena tidak sempurnanya proses enveloping. Valve pada envelope berada tidak pada area kain sehingga vacuum tidak sempurna. Ciri dari kesalahan ini bisa terlihat dari bentuk pola cetakan pada cetakan tidak sempurna. Percobaan kedua untuk pembuatan cetakan ini berjalan sempurna. Bentuk pola tercetak sempurna dan tidak terjadi robek pada cetakan saat di spreader.

Proses vulkanisir mengikuti standar flow proses. Perbedaannya hanya pada proses curing, yaitu sebelum dipasang envelope, produk yang sudah diberi kompon tapak baru dimasukan ke dalam cetakan terlebih dulu. Baru secara utuh dimasukan ke envelope.

Pengukuran kualitas cetakan diukur dari 2 item yaitu; 
1. Bentuk produk yg di hasilkan menggunakan cetakan tersebut.

2. Umur pemakaian cetakan.

Dalam percobaan yang kedua dan diteruskan hingga saat ini bentuk produk yang dihasilkan bagus sekali, terutama dari pattern \& OTD (original tread depth) yang dibentuk sama persis dengan ban baru.

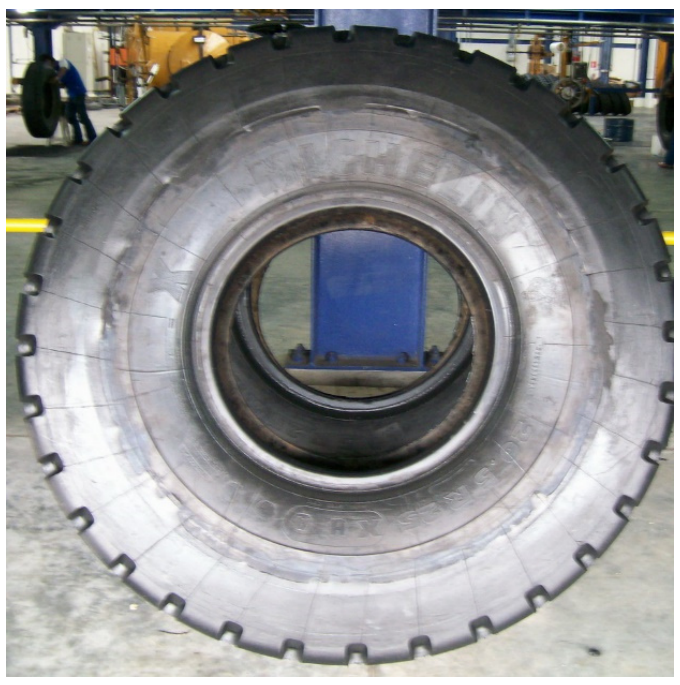

Gambar 5. Tampak samping produk akhir vulkanisir ban alat berat

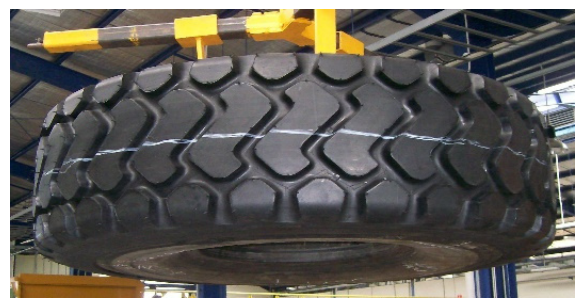

Gambar 6. Tampak depan produk akhir vulkanisir ban alat

Umur cetakan diukur dari berapa kali suatu cetakan bisa digunakan dalam produksi. Umur tersebut akan menjadi nilai pembagi biaya produksi cetakan yang akan diperhitungkan dalam harga produk. Sejak pertama kali dibuat pada bulan November 2008, mould yang pertama kali diproduksi hingga akhir Mei 2009 sudah dipakai produksi sejumlah 18 kali. Kondisi cetakan tersebut masih bagus dan masih layak untuk digunakan.

\section{Kualitas Produk Vulkanisir}

Untuk menguji produk performance retread yang dihasilkan melalui sistem cetakan karet, produk dikirim ke site untuk diadakan road test. Satuan operasi yang diukur adalah jam operasi dalam hour meter (hm). Data terkhir yang didapat dari road test bisa dilihat pada table berikut.

Tabel 4. Laporan pemeriksaan produk vulkanisir bulan mei 2009 


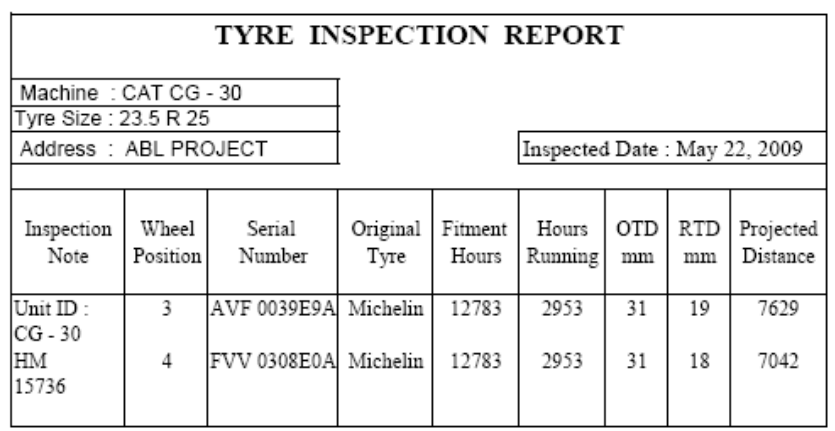

Dari laporan hasil pemeriksaan produk di atas, untuk saat ini bisa dinyatakan mempunyai prospek bagus. Life performance ban baru michelin yang digunakan pelanggan dan site yang sama rata-rata $7000 \mathrm{hm}$ (hour meter), sedangkan minimum performance yang harus diraih produk vulkanisir adalah $60 \%$ umur ban baru (sekitar 4200 $\mathrm{hm})$. Rata-rata umur produk retread cap \& groove yang dipakai di site tersebut $3000-3500 \mathrm{hm}$.

\section{KESIMPULAN}

Dengan melakukan analisa pada produk berbahan dasar karet lainnya dan dilakukan penelitian maka dilakukan uji coba pembuatan mould dengan menggunakan bahan dasar karet. Kelebihan sifat yang dimiliki karet akan meningkatkan produk vulkanisisr yang dihasilkan. Keunggulan produk yang menggunakan cetakan berbahan dasar karet ini adalah ;

1. Tread pattern yang dihasilkan sesuai dengan tapak aslinya pada ban baru.

2. Kualitas produk bagus, karena sistem cetakan karet menggunakan sistem dingin (temperatur curing rendah/maksimal $100^{\circ} \mathrm{C}$ ). Umur produk hasil metode ini di atas rata -rata umur produk dengan metode lainnya, bahkan ada banyak yang mendekati umur ban baru.

3. Operasional dalam penggunaan di kendaraan akan sesuai dengan ban baru karena bentuk pola tapak, dimensi dan ukuran sesuai dengan ban baru.

4. Harga jual yang kompetitif, dibandingkan produk cap \& goove dan precure tread. Hal ini dikarenakan biaya investasi cetakan yang lebih murah dengan kualitas produk yang lebih tinggi dari produk lainnya. Harga jual produk metode ini tetap sekitar $40 \%$ dari harga ban baru.

5. Waktu pembuatan cetakan yang cepat.

6. Biaya pembuatan cetakan sangat murah dibandingkan biaya pembuatan cetakan dari logam. Investasi yang murah menyebabkan variasi produk dari segi ukuran ban dan pola tapak yang dihasilkan bisa beragam sesuai permintaan pelanggan.

\section{INVESTASI}

Teknologi vulkanisir ban alat berat terus berkembang termasuk dengan adanya mesin-mesin berteknologi mutakhir yang sudah dibuat oleh perusahaan mesin vulkanisir terkenal. Proses pembuatan pola tapak menggunakan komputerisasi grooving membuat kualitas produk yang tinggi. Biaya material yang dibutuhkan untuk membuat 1 cetakan 23.5 - 25 sekitar Rp.15.000.000. Estimasi umur pemakaian adalah 30 kali curing, sehingga biaya produksi untuk sistem ini untuk size 23.5 R 25 sekitar Rp. 500.000.

Biaya produksi sistem cetakan karet ini lebih rendah dari sistem precure tread dan sedikit lebih mahal dari cap \& groove. Selisih biaya produksi antar cetakan karet dengan cap \& groove sangat kecil, Penghematan biaya pisau grooving selain biaya waktu dan tenaga kerja sangat kecil (ukuran 23.5 R 25 sekitar Rp 100.000).

\section{SARAN}

Uji coba dan penelitian ini bisa dilanjutkan untuk pengembangan kualitas cetkan karet yang dihasilkan. Improvisasi dan pengembangan komposisi kompon akan meningkatkan umur pemakaian cetaka karet yang dihasilkan. Biaya produksi pembuatan cetakan karet bisa dianalisa lagi dan sangat dimungkinkan untuk adanya penurunan biaya. 
Kualitas produk akhir yang dihasilkan bisa ditingkatkan dengan melanjutkan analisa proses sehingga bisa diturunkan resiko kesalahan proses yang akan mengakibatkan kegagalan produk dan penurunan kualitas produk vulkanisir ban alat berat yang dihasilkan. Selain itu sistem ini bisa analisa untuk dikembangkan pada ban truk dan bis.

\section{DAFTA PUSTAKA}

[1] Materi Kursus Bahan Jadi Karet, oleh Balai Penelitian Teknologi Karet Bogor, 2005.

[2] Harvard Business Review Journal (nov-dec1996) by Michael E. Porter.

[3] Blue Ocean Strategy by W. Chan Kim and Renee Mauborgne.

[4] Budi Daya \& Teknologi Karet, oleh Ir Tumpal H. S Siregar, Dipl. Agr dan Ir. Irwan Suhendry, NM.

[5] Pembuatan Produk Karet dan Plastik, oleh Balai Besar Kulit, Karet dan Plastik, TBKKP TPL 2008.

[6] Energetic Polymers, by How Ghee Ang and Sreekumar Pisharath.

[7] Sistem Ban dan Roda, oleh Drs. Buntarto, M. Pd.

[8] Panduan Lengkap Karet, oleh Tim Penerbit PS, Bukit Kita.com. 